\title{
Jump training in sports medicine
}

\section{Entrenamiento de salto en medicina deportiva}

\section{Rodrigo Ramirez-Campillo}

Department of Physical Activity Sciences. Universidad de Los Lagos. Santiago. Chile. Centro de Investigación en Fisiología del Ejercicio. Facultad de Ciencias. Universidad Mayor. Santiago. Chile.

doi: $10.18176 /$ archmeddeporte.00010

Through evolution, several animal species, including humans, have evolved the ability to jump. Indeed, jumping actions are common for mammals, reptiles, and insects, among others. For humans, jumping allow them to perform a wide range of activities, from dancing to moon exploration. From a sports medicine perspective, jumps have been used by athletes as a training method in preparation for competitions at least in the last 3,000 years'.

\section{Jump training exercises}

Jump training exercises (JTE) involves multi-joint drills and large muscle groups (e.g., quadriceps). Depending on the type of jump, these may involve a stretch-shortening cycle (SSC), with a considerable voluntary effort (i.e. near maximal or maximal) during the concentric portion of the jump (i.e. against the force of gravity). In addition, some jumps may also involve considerable eccentric forces upon landing, as high as 12 times body mass ${ }^{2}$. In this sense, highly trained athletes use some JTE most commonly, such as bounce drop jumps from relatively high drop heights (e.g. plyometrics). However, JTE can be adapted safely and effectively for older adults, children with cerebral palsy and Down syndrome, injured athletes, among other populations ${ }^{3}$. Adaptation strategies may involve the performance of the concentric-only portion of the jump, assistive devices (e.g., suspension training), submaximal jumps, among other. In this sense, jump training may involve a wide range of JTE, selected according to the participant's characteristics and goals, usually incorporated in a multi-component training programme (e.g., neuromuscular training), considering a long-term physical development approach.

\section{Mechanisms of adaptation}

Responses to JTE have been studied at least from the late $19^{\text {th }}$ century ${ }^{4}$. Although concentric-only JTE may be used to induce significant responses such as increased electromyographic activation (EMG), traditional JTE involves a rapid stretch of the muscle during the eccentric portion of the SSC, stimulating the stretch reflex. The stretch reflex implicates the activation of muscle proprioceptors (e.g., muscle spindle), which might facilitate the activation of muscle fibres during the concentric portion of the jump, thus greater EMG. In addition, muscle-tendon elastic components may have a role in the storing-releasing energy process during the SSC. Further, aside from muscle-spinal responses, supraspinal mechanisms contributing to the SSC are also involved during $\mathrm{JTE}^{5}$. Such acute responses to JTE accumulated over time may lead to significant adaptations ${ }^{6}$, including increased motor unit firing rate, intra-muscular coordination, inter-muscular coordination, muscle fibre hypertrophy, optimization of muscle fibres pennation angle and muscle-tendon stiffness, bone mass increase, among others. In addition, significant responses and adaptations are also achievable through JTE for biomechanical-related variables (e.g. dynamic knee control, landing impact amortization).

\section{Physical fitness adaptations}

Considering the above-mentioned physiological and biomechanical adaptations, is not surprising to observe improvements in several physical fitness outcomes after JTE programmes. In the scientific literature improvements have been reported, including muscle power, jumping (e.g. vertical, horizontal), linear sprinting (i.e. from 5-m up to 200-m), agility and change-of-direction sprint (CODs), repeated sprinting ability with and without COD, short-term endurance (e.g., up to 60-s), long-term endurance (e.g., Yo-Yo test; 3-km running time trial), reduced contact times while running, better running economy, maximal strength (e.g., dynamic; isometric), dynamic and static balance, sportspecific performance (e.g. soccer ball kicking speed), range of motion, coordination, among others ${ }^{3,7}$.

\section{Jump training in sports}

Among youth sports, for both male and female, from pre-pubertal (e.g., <8 years old) to post-pubertal age, JTE have demonstrated be- 
neficial effects (e.g., physical fitness; physiological and biomechanical outcomes) on athletes from different sports. Such sports includes soccer, basketball, handball, volleyball, tennis, hockey, sprinters, combat sports, and artistic gymnasts, among others. The beneficial effects derived from JTE have been reported usually without adverse effects. Further, compared to adults, youth seems to experience reduced symptoms of exercise-induced muscle damage and a faster recovery after JTE8. Among adult athletes, for both male and female, JTE programmes have demonstrated beneficial effects on athletes from different sports, including those previously mentioned for youth athletes, in addition to swimmers, water polo, endurance runners, ice hockey, rugby, golf, netball, among others.

\section{Jump training for health}

Although commonly associated to athletes and sport competition, JTE also have demonstrated significant favourable effects on several health-related outcomes. Such improvements includes glucose metabolism markers (e.g. fasting glycaemia and insulin), fat mass reduction, skeletal muscle hypertrophy, and acute hypotensive effect. In participants with cerebral palsy and Down syndrome, improvements have been noted in neuromuscular control and body composition. During prolonged bed rest, adapted JTE preserved muscle mass and muscle power. In older adults, adapted JTE allow improvements in balance, rate of force development, maximal strength, muscle power and EMG. In addition, adapted JTE may reduce injury risk ${ }^{9}$, through reduction in factors associated to injury, such as reduced knee abduction-adduction, improved balance, better neuromuscular control (e.g. landing technique), and reduced strength asymmetries between knee extensors/ flexors. Moreover, in case of injury, JTE can be adapted and incorporated during rehabilitation programmes (e.g. neuromuscular training). Further, the incorporation of JTE in athlete's regular training schedules may reduce their injury recurrence.

\section{Factors associated with JTE effectivity}

Participant's characteristics (e.g., JTE technique proficiency; type of sport; training age; biological maturity; sex; participant nutritional/ supplementation habits) are relevant factors for JTE prescription, particularly considering the inter-individual variability to JTE programmes. In addition, an adequate prescription of JTE should consider the total duration of the training programme (e.g., weeks), total volume (e.g., number of jump repetitions; foot contacts), and volume progression rate (e.g., weekly), in addition to taper strategies. Moreover, intensity and intensity markers such as reactive strength index, jump height, movement velocity, force-velocity profile, rating of perceived exertion, among other potential markers, should be considered during JTE prescription. Further, the type of JTE (e.g., bilateral; unilateral; vertical; horizontal; loaded; unloaded; combined), the JTE order randomization between training sessions, the specificity of JTE, sequencing (i.e., before vs after regular sport practice), and external load (e.g., heavy vs. light) should be also considered. Furthermore, the type of surface (e.g., wood; grass), recovery duration (e.g., inter-session; inter-JTE; inter-set; inter-repetition) and type of recovery (e.g., cluster set vs traditional set; active vs passive) may also affect the outcomes of a JTE programme. Additionally, the combination of JTE with other training methods, such as heavy resistance training (e.g., complex training) may be effective, potentially due to post-activation potentiation or post-activation performance enhancement mechanisms, with the advantage of combining training methods in a relatively short time period.

\section{Potential advantages over other training methods}

Although several training approaches are used to improve physical fitness and health outcomes, JTE seems to be equally (or even more) effective compared to other training methods (e.g., traditional resistance training) for the improvement of several outcomes ${ }^{3,7}$. In addition, the implementation of JTE may be inexpensive compared to other resistance training methods, requiring little or no equipment, usually involving drills with the body weight used as resistance. Additionally, JTE may be conducted in a relatively small physical space, which may be an important advantage during certain scenarios (e.g. encountering pandemic restrictions) where athletes may be forced to train at their homes ${ }^{10}$. Moreover, JTE may be considered more fun compared to other training methods (e.g., flexibility, endurance), particularly among younger athletes ${ }^{11}$. Further, JTE may reduce the risk of injury ${ }^{12}$. However, rather than an independent entity, JTE should be a component of an integrated approach to training, which targets multiple physical fitness and health attributes and aligns with the goals of long-term physical development strategies.

\section{Research gaps and future research areas}

Although JTE have been used by athletes at least in the last 3,000 years, the scientific literature regarding the acute effects of JTE seems to have emerge more recently (i.e., late $19^{\text {th }}$ century) $)^{4}$, and the study of the adaptations to JTE programmes even more recently (i.e. middle of the $20^{\text {th }}$ century) ${ }^{13}$. Indeed, there seems to be a paucity of scientific literature related to the factors associated with JTE dose-response relationship $p^{3,7}$. In addition, it is relatively common among published articles related to JTE to include small sample sizes (i.e. 10 participants per group), incomplete description of JTE, and lack of control and/or group randomization, among other methodological shortcomings. In this scenario, further efforts are needed to solve important gaps in knowledge related to JTE, particularly those related to dose-response relationship in different populations, involving long-term programmes (e.g., >12 weeks) and/or multi-component interventions, and associated mechanisms of adaptations.

\section{Bibliography}

1. Minetti $A E$, Ardigo LP. Halteres used in ancient Olympic long jump. Nature 2002;420(6912):141-2.

2. Bobbert MF. Drop jumping as a training method for jumping ability. Sports Med 1990;9(1):7-22. 
3. Ramirez-Campillo R, Moran J, Chaabene H, et al. Methodological characteristics and future directions for plyometric jump training research: A scoping review update. Scand J Med Sci Sports. 2020;30(6): 983-97.

4. Marey M, Demeny M. Locomotion hunaine, mecanisme du saut. CR Acad Sci (Paris) 1885;101:489-94.

5. Taube W, Leukel C, Gollhofer A. How neurons make us jump: the neural control of stretch-shortening cycle movements. Exerc Sport Sci Rev. 2012;40(2):106-15.

6. Markovic G, Mikulic P. Neuro-musculoskeletal and performance adaptations to lowerextremity plyometric training. Sports Med 2010;40(10):859-95.

7. Ramirez-Campillo R, Alvarez C, Garcia-Hermoso A, et al. Methodological characteristics and future directions for plyometric jump training research: A scoping review. Sports Med. 2018;48(5):1059-8

8. Marginson V, Rowlands AV, Gleeson NP, Eston RG. Comparison of the symptoms of exercise-induced muscle damage after an initial and repeated bout of plyometric exercise in men and boys. J Appl Physiol. 2005:99(3):1174-81.
9. HewettTE, Lindenfeld TN, Riccobene JV, Noyes FR. The effect of neuromuscular training on the incidence of knee injury in female athletes - A prospective study. Am J Sports Med. 1999;27(6):699-706

10. Gentil P, Ramirez-Campillo R, Souza D. Resistance training in face of the coronavirus outbreak: time to think outside the box. Frontiers in physiology. 2020;11(859).

11. Ward P, Hodges N, Williams AM. The road excellence in soccer: Deliberate practice and the development of expertise. High Ability Studies. 2007;18(2):119-53.

12. ter Stege MHP, Dallinga JM, Benjaminse A, Lemmink KAPM. Effect of interventions on potential, modifiable risk factors for knee injury in team ball sports: a systematic review. Sports Medicine. 2014;44(10):1403-26.

13. Berger RA. Effects of dynamic and static training on vertical jumping ability. Res $Q$ 1963;34:419-24

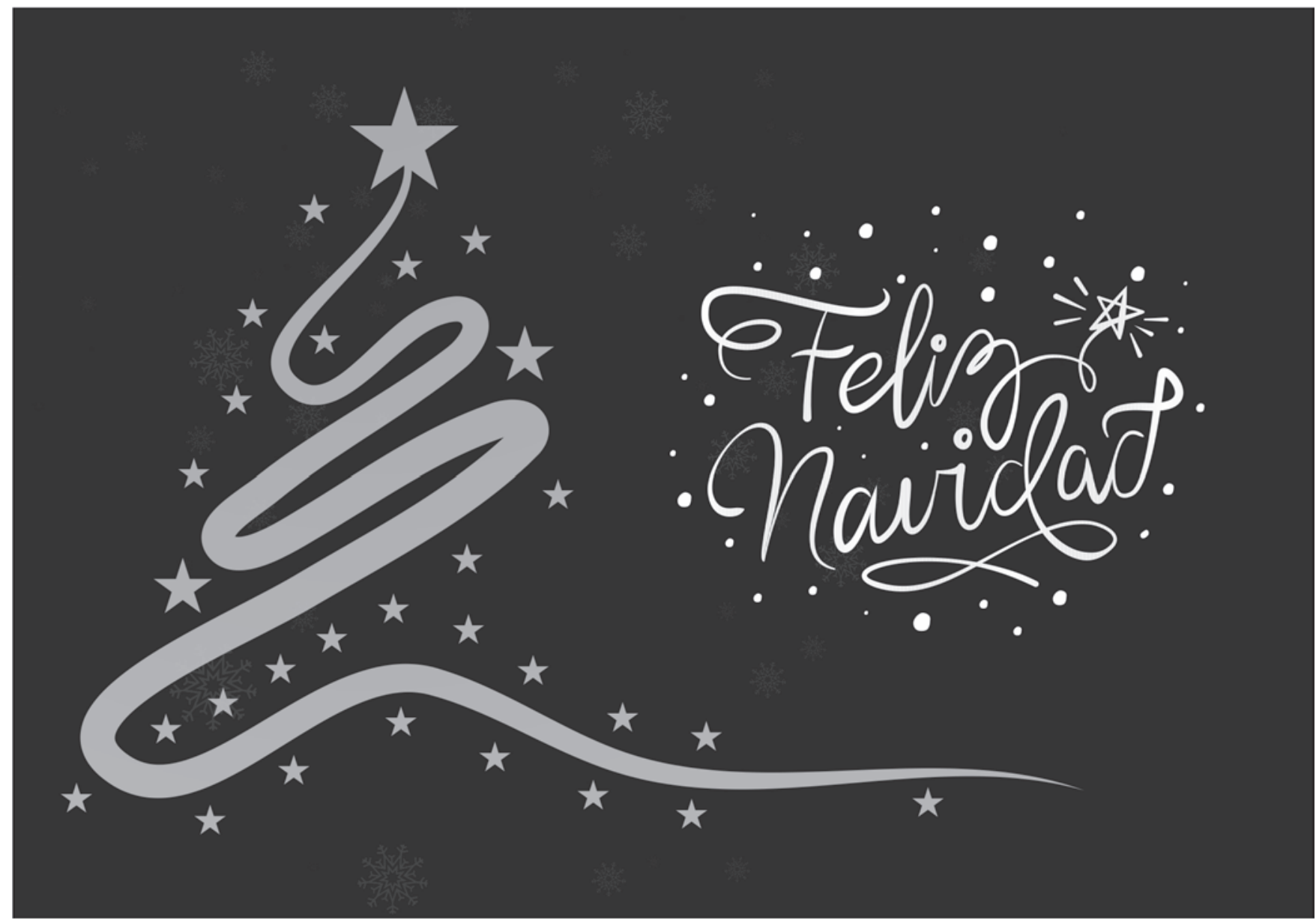




\section{Analizador Instantáneo de Lactato arKґay Lactate Pro

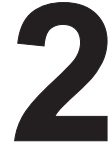 \\ LT-1730}

- Sólo 0,3 $\mu$ l de sangre

- Determinación en 15 segundos

- Más pequeño que su antecesor

- Calibración automática

- Memoria para 330 determinaciones

- Conexión a PC

- Rango de lectura: 0,5-25,0 mmol/litro

- Conservación de tiras reactivas a temperatura ambiente y

- Caducidad superior a un año

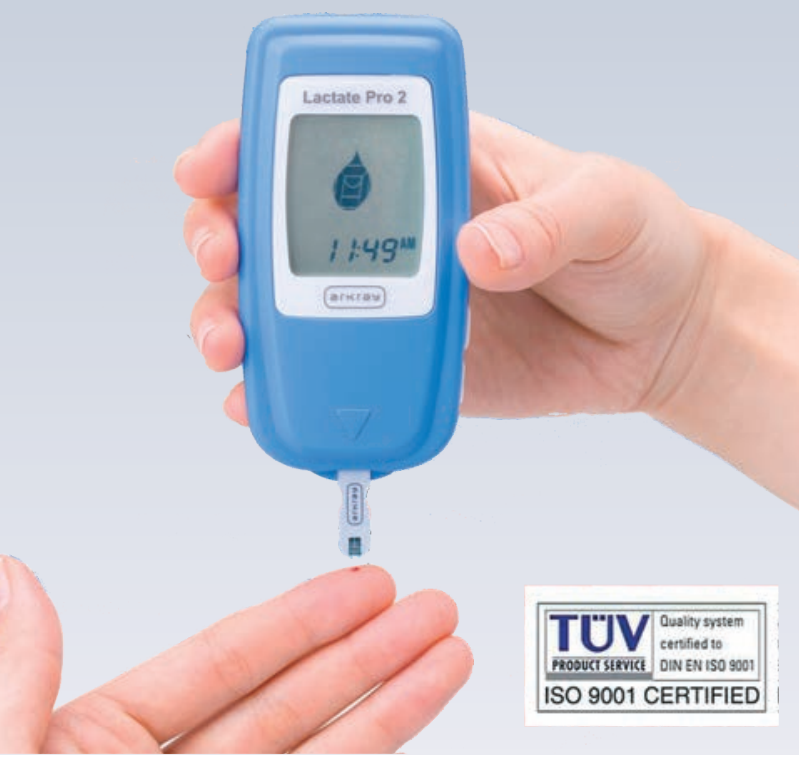

Importador para España:

finciscoj, bermell ELECTROMEDICINA

wuwbermellelectromedicino com EQUPOS PARA EL DEPORTEY Y LA MEDICINA DEL DEPORTE c/ Lto. Gabriel Miro, 54, ptas. 7 y 9 46008 Valencia Tel: 963857395

Móvil: 608848455 Fax: 963840104 info@bermellelectromedicina.com www.bermellelectromedicina.com

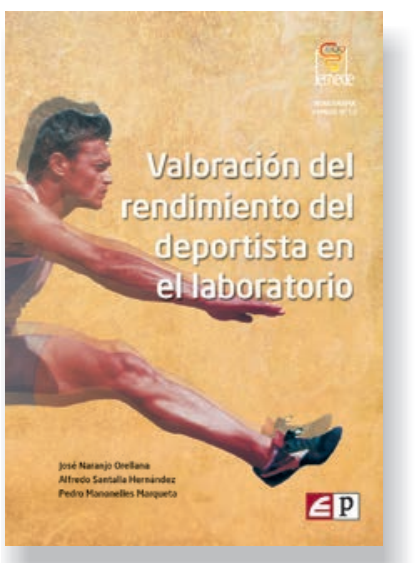

Monografías Femede $n^{\circ} 12$ Depósito Legal: B. 27334-2013 ISBN: 978-84-941761-1-1 Barcelona, 2013 560 páginas.

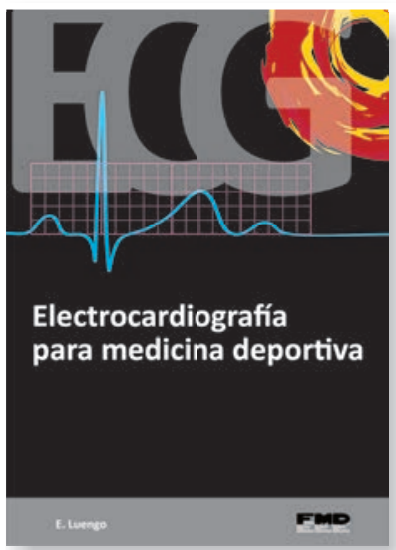

ISBN: 978-84-941074-7-4

Barcelona, 2013

75 páginas. Color

\section{Índice}

Foreward

Presentación

1. Introducción

2. Valoración muscular

3. Valoración del metabolismo anaeróbico

4. Valoración del metabolismo aeróbico

5. Valoración cardiovascular

6. Valoración respiratoria

7. Supuestos prácticos

Índice de autores

\section{Índice}

\section{Introducción}

1. Actividad mioeléctrica

2. Componentes del electrocardiograma

3. Crecimientos y sobrecargas

4. Modificaciones de la secuencia de activación

5. La isquemia y otros indicadores de la repolarización

6. Las arritmias

7. Los registros ECG de los deportistas

8. Términos y abreviaturas

9. Notas personales

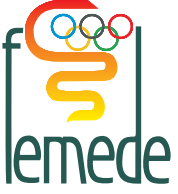

ernede 